\title{
La dimensión mítica de los personajes vanguardistas. Una reflexión en torno a la teoría de Ortega y Gasset
}

\author{
Rosa FERNÁNDEZ URTASUN \\ Universidad de Navarra \\ rosafu@unav.es
}

\section{RESUMEN}

En el realismo de finales del XIX se consolida el desarrollo de los personajes novelescos, pero muy poco tiempo después se produce un giro en la narrativa hacia la abstracción que induce a Ortega y Gasset a reflexionar sobre cuáles son las características que definen un personaje literario. En Meditaciones del Quijote (1914), La deshumanización del arte e Ideas sobre la novela (ambos de 1925) hace un análisis histórico que concluye ofreciendo un diagnóstico de la literatura contemporánea. Muchos de los narradores vanguardistas, formados a su sombra, tienen en cuenta sus escritos y experimentan con sus propuestas. En este proceso el mito juega un papel principal, como sustancia de lo poético y como sustrato cultural de muchos de los protagonistas de la novela experimental de los años 20.

Palabras clave: novela vanguardista, mito, Ortega y Gasset

\begin{abstract}
In the late nineteenth-century realism consolidates the development of fictional characters, but shortly after there is a turn in narrative to abstraction that induces Ortega y Gasset to reflect on what are the defining characteristics of a literary character. In Meditations on Quixote (1914), The Dehumanization of Art and Ideas on the novel (both from 1925) he makes a historical analysis that concludes with an assessment of contemporary literature. Many of the avant-garde narrators formed around him take into account his writings and experiment with his proposals. In this process, myth plays a major role, both as the poetic substance and as the cultural foundation of many of the protagonists of the experimental 20's novel.
\end{abstract}

Keywords: avant-garde novel, myth, Ortega y Gasset

SUMARIO: 1. Del mito y el héroe; 2. La novela contemporánea; 3. Los personajes míticos en la novela vanguardista. 
La construcción de personajes complejos, bien trabados, profundos, descritos con todo detalle, tanto en lo que se refiere a su aspecto externo y psicología como a su origen y sus relaciones, fue uno de los logros de la novela de finales del siglo XIX. Parecía en este sentido que la literatura había alcanzado una cima en la que se podría mantener indefinidamente. Sin embargo, con el cambio de siglo empiezan a aparecer novelas con protagonistas tan esquemáticos, irreales y desconcertantes como los que crean Unamuno o Pirandello. Este rápido cambio ofrece al filósofo Ortega y Gasset un punto de reflexión que aborda ya desde su primera obra, Meditaciones del Quijote (1914), y continúa en La deshumanización del arte e Ideas sobre la novela (ambos de 1925). En estas obras revisa, no de manera directa pero sí explícitamente, la configuración de los personajes desde los comienzos de la novela, explorando qué determina la creación de un personaje literario. Sus reflexiones serán recibidas por los escritores de los años 20 unas veces como un diagnóstico y otras como una orientación magisterial.

\section{Del mito y el héroe}

No es sorprendente encontrar en los panoramas que describen la narrativa española de los años 20 opiniones como la de Magnien, quien defiende que el rótulo «narrativa de vanguardia» comprende una serie de obras publicadas por autores que, «guiados por Ortega y Gasset, hallan en la Revista de Occidente, desde su creación, acogida, orientación teórica e incluso, para algunos, editorial» ${ }^{1}$. Suele subrayarse el impulso que gracias a este filósofo cobró la reflexión teórica sobre la literatura a propósito de La deshumanización del arte o Ideas sobre la novela. Sin embargo, a Meditaciones del Quijote, aun siendo un libro trabajado desde el ámbito de la teoría ${ }^{2}$, no se le ha dado la importancia que de hecho merece en este contexto ${ }^{3}$. En esta obra hace Ortega un somero recorrido por la evolución de la literatura, partiendo de la épica hasta llegar al realismo. Muestra cómo a través de los siglos van cambiando los personajes que protagonizan las obras, de dioses y héroes a hombres y mujeres corrientes, sin relieve, para llegar a reducirse incluso a simples abstracciones.

En la primera de las Meditaciones del Quijote Ortega quiere mostrar por qué la novela de Cervantes supone el comienzo de la novela contemporánea. Para ello se remonta al mundo clásico, que no solo funda nuestra cultura, sino que aporta lo que

${ }^{1}$ B. Magnien (2006), p. 276.

${ }^{2}$ L. Beltrán Almería (2009), y J.C. Mainer (2010), p. 53.

${ }^{3}$ A pesar de esto, es un ensayo ambicioso en el que plantea cuestiones que considera la base de toda su filosofía (J. Marías, 2005, p. 18-19). 
considera el núcleo de toda obra literaria: el mito ${ }^{4}$. En la épica clásica, los protagonistas son héroes, criaturas únicas de perfiles extraordinarios precisamente por su singularidad:

Sólo un Aquiles ha existido y una sola Helena; solo una guerra al margen del Scamandros. Si en la distraída mujer de Menelao creyéramos ver una moza cualquiera, requerida de amores enemigos, Homero habría fracasado. Porque su misión era muy circunscrita — no libre como la de Ghiberti o Flaubert-, nos ha de hacer ver esta Helena y este Aquiles, los cuales, por ventura, no se parecen a los humanos que solemos hallar por los trivios ${ }^{5}$.

Es importante para la tesis de Ortega la precisión final, la lejanía entre cualquiera de estos personajes y los seres ordinarios. A pesar de sus defectos y sus limitaciones (el comportamiento de los dioses clásicos muestra debilidades propias del vulgo), la distancia entre esos héroes y nosotros es infranqueable. La razón de este abismo estriba en su dimensión mítica, «que era precisamente lo que permitía alejarse del mundo de las apariencias, ir más allá de las circunstancias, para acceder a lo esencial (los principios y las causas)» (p. 192). Las acciones del mundo clásico, en su heroísmo y en su vulgaridad, no eran fruto solamente de la libre iniciativa de sus protagonistas, sino que se entendían como una respuesta. Los mitos contaban historias trascendentes (con matices religiosos) de origen oral e intemporal. De ahí que a estos héroes clásicos les sea intrínseco el valor poético: su belleza radica en su singularidad trascendente. Esta fuerza hace que los poetas vuelvan una y otra vez sobre ellos, ofreciendo diversas variantes sobre sus hechos heroicos, sus amores y sus hijos, sin plantearse la necesidad de crear nuevos personajes o de ser originales.

Esta cosmovisión del mundo clásico, según Ortega, se extiende hasta el final de la Edad Media. Entonces, «cuando la visión del mundo que el mito proporciona es derrocada del imperio sobre las ánimas por su hermana enemiga la ciencia, pierde la épica su empaque religioso» (p. 202): se dejan de lado las preguntas esenciales y la trascendencia mítica da paso a otro tipo de cuestionamientos sobre el mundo de carácter descriptivo, científico.

Hay un tiempo de transición en el que la narrativa se mueve hacia la acción y presenta relatos de aventuras. El giro definitivo lo da Cervantes al introducir en el universo de la ficción las coordenadas espacio temporales de su propia época, del mundo en el que vive. Con él desaparecen definitivamente el mundo mítico y sus

\footnotetext{
${ }^{4}$ Para comprender el alcance del mito en la teoría literaria de Ortega puede consultarse R. Fernández Urtasun (2012), p. 70-73.

${ }^{5}$ J. Ortega y Gasset (2005), p. 198. Cuando no haya posibilidad de confusión entre las diferentes obras, las referencias a Ortega irán en el cuerpo del texto.
} 
héroes; la novela que inaugura es un microcosmos que reproduce, con las limitaciones propias de toda reducción, la vida de los hombres ordinarios:

Si las figuras épicas son inventadas, si son naturalezas únicas e incomparables, que por sí mismas tienen valor poético, los personajes de la novela son típicos y extrapoéticos; tómanse, no del mito, que es ya un elemento o atmósfera estética y creadora, sino de la calle, del mundo físico, del contorno real vivido por el autor y por el lector (pp. 198-199).

Estos hombres, privados de la singularidad trascendente, serán «típicos» y, por tanto, «extrapoéticos». De ahí el esfuerzo de Ortega por tratar de comprender donde está la esencia poética de los protagonistas de las novelas contemporáneas. Parte el filósofo de la convicción de que los personajes «realistas», en cuanto tales, no pueden atraernos en sí mismos. Sin embargo, nos cautiva verlos actuar, ir avanzando en su conocimiento y seguir sus hazañas (pp. 204-205).

¿Qué sucede en la transición de la realidad al papel? Por un lado, que se abre la puerta al mundo de la imaginación el cual, como bien explica Julián Marías al comentar esta idea, no puede simplemente yuxtaponerse al de la realidad sino que debe ser sintetizado por un «tercer punto de vista, superior a los términos de la cuestión» (p. 212). Esta síntesis se encarna en la obra de Cervantes en la creación del personaje de don Quijote, y alcanza un mayor grado de eficacia con el contrapeso de Sancho Panza.

Por otro lado, un análisis detenido descubre que aunque la cosmovisión mítica desaparezca, el mito sigue siendo el núcleo o la esencia de lo poético: «el mito es siempre el punto de partida de toda poesía, inclusive de la realista. Solo que en esta acompañamos al mito en su descenso, en su caída. El tema de la poesía realista es el desmoronamiento de una poesía» (p. 221).

La corriente de esta caída tiene su centro en los personajes. Los protagonistas de la nueva novela mantienen elementos originarios, míticos, pero la fuerza de la realidad hace que estos elementos se muestren en su caída, precisamente en movimiento de descenso, en actitud activa de subversión. Esto supone una mirada del autor sobre la realidad no directa sino oblicua. Este mirar de soslayo permite que la representación de la realidad se transforme en un mundo de ficción. De tal modo insiste Ortega en este aspecto (y debió hacerlo también en su magisterio oral), que, como veremos, gran parte de las novelas modernas escritas en el ámbito de su influencia tendrán como protagonistas a personajes míticos en su proceso de subversión.

Como es lógico, un cambio tan nuclear afecta a la configuración de los personajes modernos en más de un aspecto. Uno de los más significativos es el paso de la tensión trágica propia del mundo antiguo al tono cómico predominante en la novela contemporánea. Ortega considera que todavía no tenemos las herramientas necesarias para conocer el significado profundo de la tragedia en el mundo griego, 
sus connotaciones religiosas y políticas, el tipo de vivencia que producía en los espectadores. Pero al estudiar obras más recientes, como las de Shakespeare, deduce el filósofo que la tragedia no reside en la fatalidad sino en la voluntad libre de los personajes, en esa potencia del ser humano en la que confluyen la realidad y la posibilidad de cambiar su curso.

Los protagonistas de los relatos clásicos, por tanto, tal y como nos han llegado, asumen libremente el papel que les toca jugar, «pertenecen al mismo orbe que sus deseos» (p. 226), no se encuentran divididos entre sus ilusiones y la realidad. En la literatura contemporánea, sin embargo, es héroe quien no se contenta pasivamente con la realidad de la que forma parte, con las imposiciones de la herencia y las costumbres, sino que busca radicar en sí mismo el origen de sus actos (p. 227). Este punto adquiere una nueva claridad cuando Ortega contrapone al héroe la mirada del plebeyo, de quien actúa por necesidad y no comprende qué puede llevar a un hombre a emprender por voluntad propia acciones esforzadas (p. 235). Son precisamente los «instintos plebeyos» que todos llevamos dentro los que nos permiten mirar de manera oblicua al héroe, convirtiéndolo a través del pragmatismo en un personaje cómico. Precisamente porque «el carácter de lo heroico estriba en la voluntad de ser lo que aún no se es, tiene el personaje trágico medio cuerpo fuera de la realidad. Con tirarle de los pies y volverle a ella por completo, queda convertido en un carácter cómico» (pp. 237-238). Cuanto más peso tengan el materialismo y la necesidad en el realismo, mayor será la carga cómica. De ahí que el libro aborde la confluencia entre teorías científicas y literarias en el realismo y el naturalismo de finales del siglo XX. Las teorías de Darwin aprisionan, afirma Ortega, «lo vital —nuestra última esperanza - dentro de la necesidad física. La vida desciende a no más que materia. La fisiología a mecánica» (p. 244). En este tipo de literatura el personaje pierde todo asomo de libertad, de capacidad de decidir sus actos, y pasa a ser una extensión del mundo físico, de modo que en ella la descripción de ambientes se hace equivalente a la descripción de acciones.

\section{La novela contemporánea}

La primera «Meditación del Quijote» acaba precisamente aquí, anunciando de manera implícita la desaparición del personaje, la disolución de la figura en el ambiente. Ortega no sigue desarrollando lo que iba a ser una serie de tres meditaciones, pero de hecho se puede establecer una línea de continuidad entre las reflexiones que hace el filósofo a propósito del realismo, la verosimilitud y el determinismo, y las que ofrece diez años más tarde al abordar la vanguardia. No es casualidad que estas últimas se titulen La deshumanización del arte.

En esta segunda obra, el punto de partida de la especulación no es la literatura sino las artes plásticas, pero muchas de las propuestas teóricas son igualmente válidas para la novela. En pocos años se produce en el arte un cambio de dirección impulsado por una fuerte tendencia centrípeta. Los artistas se fijan de manera específica en su quehacer y el arte hace ostensible esta reflexión a través de modos 
verdaderamente novedosos. El elemento central sobre el que pivota el cambio, según Ortega, es la desaparición de la figura humana. Mantiene, como en Meditaciones del Quijote, que el interés natural de la mayoría de los seres humanos al acercarse a una obra literaria se dirige hacia sus protagonistas. Sin embargo, «alegrarse o sufrir con los destinos humanos que, tal vez, la obra de arte nos refiere o presenta es cosa muy diferente del verdadero goce artístico. Más aún: esa ocupación con lo humano de la obra es, en principio, incompatible con la estricta fruición estética» ${ }^{6}$. Como en su obra anterior afirma que «se trata de una cuestión de óptica» (p. 50), en este caso de enfoque: al fijar nuestra atención sobre aquello que tenemos en un primer plano el fondo se nos hace borroso, y viceversa. Estos dos planos son, en el caso de la novela, la ficción y la realidad. Cuando nos conmueven los gozos y dolores de los personajes, estamos interpretando la obra literaria como realidad. Solamente cuando contemplamos el texto desde la distancia que esa palabra implica somos capaces de apreciar su valor artístico, su valor de obra de ficción.

Considera el filósofo que no todo el mundo es capaz de pasar del primer enfoque, natural, al segundo, que exige una formación. Recurre aquí también a la distinción de clases para ilustrar este punto: igual que la sociedad estaba «dividida en dos capas: los nobles y los plebeyos, existió un arte noble que era "convencional”, "idealista”, esto es, artístico, y un arte popular que era realista y satírico» (p. 52, nota 2). Lo que sucede en las primeras décadas del siglo XX es que desaparece el arte popular, con el consiguiente desconcierto del pueblo. A los artistas no les preocupa que el arte se vuelva cada vez más elitista y hermético, su objetivo es que todos los ojos se vuelvan sobre el arte en sí y para ello se esfuerzan en la «eliminación progresiva de los elementos humanos, demasiado humanos, que dominaban en la producción romántica y naturalista» (p. 52). Esta afirmación muestra la convicción de que, incluso como parte del ambiente, la figura humana seguía teniendo una fuerza sustantiva que arrastraba tras de sí cualquier tipo de forma viva. Si el arte quería ser abstracción de sí mismo era necesario eliminar de él cualquier rastro de referencialidad natural.

Ortega insiste en que esta referencia nunca puede desaparecer del todo porque es imprescindible para la inteligibilidad de cualquier obra. Más aún si hablamos de novela, una estructura artística que no puede ser reducida totalmente a elementos abstractos. En este caso, el escritor que quiera llamar la atención sobre el carácter artificial de su obra podrá hacerlo deformando la realidad a través de múltiples recursos, entre los que el filósofo destaca las metáforas y el cambio de perspectiva habitual. Con todo, el argumento más «artístico» consistirá siempre en analizar la ficción desde sí misma. Así, en Seis personajes en busca de autor, Pirandello «logra

${ }^{6}$ J. Ortega y Gasset (2008), p. 50. 
interesarnos por unos personajes como tales personajes; es decir, como ideas o puros esquemas» (p. 73). Se trata de resaltar el proceso de construcción y el carácter de constructo de la obra. Otro modo de trabajar este aspecto, eficaz entre sus seguidores, será utilizar personajes míticos, referentes cultos que no necesitan ser descritos (sus rasgos pueden reducirse a una mera evocación) y cuya mera localización en un tiempo contemporáneo produce un fuerte efecto de descontextualización.

Curiosamente Ortega prescinde de este panorama de cambio al exponer sus Ideas sobre la novela, ensayo publicado en el mismo volumen que La deshumanización del arte. En esta obra, que dice escribir como simple aficionado a la literatura, adopta la perspectiva del lector común, de quien se acerca a una novela con el único interés de dejarse llevar por el placer de leerla. Sin embargo, según va avanzando la obra, su modo de escribir categórico y sus análisis sobre novelas contemporáneas dan a este trabajo un cierto carácter magisterial, de orientación sobre la dirección que, a su juicio, debe seguir la novela del siglo XX.

Es muy significativo a este respecto el capítulo dedicado al «hermetismo». Con este término Ortega no se refiere a esa «voluntad de dificultad» que atraviesa el arte contemporáneo sino precisamente al fenómeno contrario. En este capítulo, el filósofo describe el momento en el que «damos fin a la lectura de una gran novela. Nos parece que emergemos de otra existencia, que nos hemos evadido de un mundo incomunicante con el nuestro auténtico» ${ }^{7}$. El novelista ha conseguido de tal modo introducirnos en las redes de su ficción que ha anulado toda distancia. No hay posibilidad de contemplación, de reflexión sobre la voluntad de estilo, ni siquiera de consideraciones de tipo social o metafísico. La buena novela ha aislado al lector de sus preocupaciones ordinarias, lo ha anestesiado en la intrascendencia, que Ortega considera «el imperativo genérico del arte» (p. 47). Así, adoptando el punto de vista del pueblo, el filósofo apunta sin vacilar en una dirección opuesta a la que seguía el arte de su época. Por supuesto, acepta que una buena novela pueda suscitar todo tipo de resonancias vitales, pero siempre de manera secundaria (p. 48). Desde este punto de vista juzga la vigencia de las obras de Stendhal, Dostoievsky o Proust, y los propone como modelos para la creación de escritos que formen un horizonte «hermético», ajeno a cualquier intención política, ideológica, simbólica o satírica.

Dentro de este universo cerrado, y siguiendo la lógica «plebeya», Ortega subraya la importancia del personaje como elemento nuclear del relato. Insiste en que la trama es un elemento necesario, pero su función debe ser la del cañamazo que forma el sustrato: estructurar de manera invisible. Las acciones solo interesan en cuanto que son determinados sujetos quienes las llevan a cabo. En la construcción de estos personajes se juega el novelista la eficacia de su obra. De este modo recoge

\footnotetext{
${ }^{7}$ J. Ortega y Gasset (2005), p. 45.
} 
lo que ya había afirmado en Meditaciones del Quijote, pero dejando de lado las referencias al mito y a su subversión, que formarían parte de una perspectiva diferente, «artística» o «idealista», por mantener sus mismos términos.

La construcción de los personajes es un aspecto al que el filósofo dedica varios capítulos. Siguiendo una corriente teórica que se estaba extendiendo en su época (el show, don't tell de Henry James) subraya la importancia de que los lectores puedan seguir las acciones de los personajes guiados por su propio juicio y no por las explicaciones del narrador. El escritor debe evitar «referirnos lo que un personaje es: hace falta que lo veamos con nuestros propios ojos» (p. 20). En parte, porque de este modo las obras ganan en credibilidad y verosimilitud. Y en parte también porque uno de los grandes atractivos de la novela es tratar de aprehender la personalidad de sus protagonistas: «nos complace verlos directamente, penetrar en su interior, entenderlos, sentirnos inmersos en su mundo o atmósfera» (p. 20). De ahí que Ortega comprenda la novela como un «género moroso». Cuantos más detalles tengamos sobre el modo de pensar y actuar de los personajes, más deleitable resultará la obra. Asimismo, cuanto más originales y sugestivas sean las personalidades que el escritor presenta, mayor será el placer al conocerlas.

En este sentido, insiste Ortega en no confundir lo atractivo con lo fabuloso: «la vida es precisamente cuotidiana. No es más allá de ella, en lo extraordinario, donde la novela rinde su gracia específica, sino más acá, en la maravilla de la hora simple y sin leyenda» (p. 43). La realidad es imprescindible en la novela moderna, es su materia. Lo que hace de la realidad novela es la forma:

La materia no salva nunca a una obra de arte y el oro de que está hecha no consagra a la estatua. La obra de arte vive más de su forma que de su material y debe la gracia esencial que de ella emana a su estructura, a su organismo. Esto es lo propiamente artístico de la obra y a ello debe atender la crítica artística y literaria. (p. 31)

El autor debe saber manipular la realidad para hacer de ella una obra de arte. En el caso de los personajes, el papel del narrador es clave pare dosificar la información de modo que una parte importante de la intriga de la novela sea precisamente el hacerse con la personalidad de los protagonistas. Ortega considera que la nueva novela debe avanzar precisamente en esta dirección, valiéndose para ello de todas las herramientas que proporciona la ciencia: «en los últimos cincuenta años tal vez nada ha progresado tanto en Europa como el saber de almas. Por vez primera existe una ciencia psicológica» (p. 52), aplicándolas a las criaturas surgidas de la imaginación: «en la invención de almas interesantes veo yo el mejor porvenir del género novelesco» (p. 56).

La contradicción entre las tesis planteadas en ambos ensayos es muy llamativa, y conviene precisar que Ortega no se decanta por ninguna de ellas. Es al escritor a quien toca decidir si construir sus relatos siguiendo los dictados de la historia del 
arte o crear sus novelas para el disfrute del pueblo. En los cuentos y novelas que se analizan en este trabajo (una pequeña muestra entre muchos otros ejemplos coetáneos de planteamiento similar), la apuesta por los personajes míticos determina un tipo de escrito en el que la construcción ficticia, no realista, resulta evidente. Sin embargo, sus autores tienen muy en cuenta la necesidad de atraer al lector y lo harán a través de un tono cómico y distendido, otorgando a sus protagonistas una psicología inesperada y cuidando con mucho detalle los aspectos formales en sus recursos más lúdicos.

\section{Los personajes míticos en la novela vanguardista}

Se entiende, por lo dicho anteriormente, que la lectura conjunta de $L a$ deshumanización del arte e Ideas sobre la novela tuvo que resultar desconcertante para los novelistas de los años 20, del mismo modo que resulta chocante hoy. La primera obra, que mostraba el punto de vista del artista, apuntaba hacia un tipo de obra de arte (de narración) muy centrada sobre sí misma, que debía hacer explícito su proceso de construcción y tratar de eliminar las referencias humanas. La segunda, escrita desde la perspectiva del lector, declaraba categóricamente que la grandeza de una novela resulta de la creación de un mundo cerrado en el que los avatares intrascendentes de sus protagonistas se muestran sin intervención del narrador. Esta apuntaba hacia el desarrollo de la psicología de los personajes como horizonte de creación.

Tal divergencia refleja la fuerza del contraste que suponía el arte contemporáneo frente a la manera tradicional de leer y disfrutar los textos. También los narradores se debatían entre el atractivo de la novedad y el afán de escribir novelas que provocaran el deleite y la admiración de los lectores. Por un lado, la voluntad de estar en vanguardia, unida al influjo de autores inmediatamente anteriores como Unamuno o Azorín en España, y James, Proust, Giraudoux o Joyce más allá de las fronteras, atrajeron el mayor peso compositivo en la dirección del arte nuevo ${ }^{8}$. Por otro, las novelas españolas de los años 20 estuvieron atentas a facilitar el acercamiento al lector a través de una serie de características que se convirtieron en señal de identidad de la generación.

En suma, lo que de hecho encontramos en las novelas es una apuesta por una obra intelectual, que opera con referentes cultos y muestra su carácter artificial, pero que al mismo tiempo contempla la realidad a través de una mirada oblicua en principio subversiva, que da un giro lúdico a sus abundantes recursos retóricos (especialmente imágenes y metáforas) y que imprime un tono cómico al conjunto.

En lo que se refiere a los personajes, la opción por el arte «artístico» conduce a los escritores a idear figuras que, como define Ortega las de Pirandello, no sean sino

${ }^{8}$ B. Magnien (2006), pp. 278-281; D. Ródenas de Moya (1997), pp. 41-42. 
«ideas o puros esquemas». Para satisfacer al lector, procuran que al mismo tiempo tengan una psicología atractiva, sean «almas interesantes». Ambas premisas son aparentemente incompatibles; por eso los autores para solventar este conflicto en muchas ocasiones erigen como protagonistas de sus obras a héroes y dioses del Olimpo o a seres humanos corrientes que se identifican explícitamente con ellos. De este modo pueden contar con personajes arquetípicos, esquemáticos y definidos, y actualizarlos a través de la psicología compleja de la época contemporánea.

Creo que resulta esclarecedor abordar esta sintomática recuperación de los mitos como bisagra entre modernidad y tradición desde la perspectiva de Ortega y contrastarla con las obras que se escribieron en España en estos años anteriores a la guerra, en muchas ocasiones bajo su auspicio y patrocinio.

El recurso al mito aparece ya en Vísperas del gozo (1926), de Salinas, la primera obra de la colección «Nova Novorum» de la editorial Revista de Occidente. Se trata de un volumen que hoy podríamos adscribir al subgénero «ciclo de cuentos»: está compuesto por una serie de relatos breves, independientes, unidos entre sí por esa cercanía del objeto anhelado al que hace alusión el título. Son textos que reflexionan sobre el tiempo y la espera, y sobre cómo se viven los hechos que suceden en ese espacio de deseo. El tema en sí es ya una propuesta con distancia, no pretende crear una realidad autónoma propia sino plantear una serie de situaciones análogas que provocan una meditación sobre el modo que tenemos de percibir la realidad. La propuesta es de orden intelectual, pero el tono de los relatos es realista y está tratado con donaire y sentido del humor.

Aunque hay alusiones a los dioses olímpicos en varios relatos, su presencia es especialmente marcada en «Cita de los tres». En este relato, Matilde, comenta mirando a Ángel (el protagonista), que irá a las seis a la catedral a ver la estatua de Alfonso de Padilla. El tiempo de espera adquiere desde entonces un protagonismo que se personifica con una alusión indirecta a Cronos, a través de la cual se percibe el tiempo como ganancia: tras una larga digresión sobre los relojes de la ciudad, que nunca suenan de manera simultánea, el narrador habla del tiempo arrebatado en «ese cuarto de hora de retraso que trae siempre el tren cuando se marcha nuestro amigo, hurto hecho al tiempo, bien robado y bien guardado, que nunca recobrará, como Zeus, el hijo escapado»" .

Más interesante para el tema que aquí se trata son las comparaciones de los protagonistas con los dioses. Matilde no llega a la hora prevista y Ángel, para convencerse de que tiene sentido seguir esperando, se dice: «aún puede venir, apenas sí son las seis» (866). Al escuchar sus pensamientos materializados, hechos palabra, se convence de su realidad y se regocija, embelesado, en su sentido, convirtiéndose así en un «Narciso sin agua y con amante» (866). El narrador pasa a

${ }^{9}$ P. Salinas (2007), p. 865. 
una dimensión metatextual en la que el personaje se reconoce sólo palabra y cierra el círculo de sentido sobre sí mismo.

Sin embargo, la relación de la palabra con la realidad es elástica y si, por un lado, la voz materializada parece adquirir entidad de verdad y confirmar el deseo, por otro, el reconocimiento de la voz como algo distinto de la realidad acentúa la desconfianza en la palabra, que no es más que ficción. Como en los relatos originarios del mito, el ensimismamiento de Narciso tiene un efecto sobre Eco:

Pero hay voces, y ésta era una de ellas, con doble eco: uno afuera, en las rocas, en las paredes, que las repite tal como las queríamos, fidelísimo, y otro subrepticio, interior y extraño, con el que no contábamos, que deforma nuestras palabras y las devuelve sonando a todo lo contrario de lo que decían ${ }^{10}$.

En este caso, el Eco no es sino una parte del yo del protagonista: la duplicidad de personajes del mito es en el relato moderno el desdoblamiento del sujeto. Por eso, el proceso de desmaterialización de Eco, tal y como lo relata Ovidio, podría servir para describir la deshumanización del personaje que se da en este relato de Salinas: Eco, antes de conocer a Narciso, «era un cuerpo, no una voz», pero tras su rechazo

las insomnes preocupaciones amenguan su cuerpo que mueve a compasión, y la delgadez contrae su piel, y todo el jugo de su cuerpo se va hacia los aires; solamente le quedan la voz y los huesos: permanece la voz; cuentan que los huesos adoptaron la figura de una piedra. A partir de ese momento se oculta en los bosques y no es vista en montaña alguna, es oída por todos: el sonido es el que vive en ella ${ }^{11}$.

Lo que en Ovidio es metamorfosis en Salinas se convierte en reducción del personaje a dimensión metatextual. De este modo, como en Seis personajes en busca de autor, de Pirandello o Niebla de Unamuno, el protagonista moderno no es sino un esquema de sí mismo.

También Matilde recibe su correlato mítico. Su transmutación en Diana cuando llega a la iglesia (a las siete, con una hora de retraso) transforma a su vez todo lo que la rodea:

Pero de pronto el cortinón de la puerta del fondo de la iglesia se alzó: por allí entraban desatados, alegres, como una jauría, un tropel de rayos de sol, dorados, rojos, leonados, aullantes, saltando todos alrededor de una figura encendida y gallarda de mujer, rubia y esbelta, que traía bajo el brazo un carcaj parecido a una

\footnotetext{
${ }^{10}$ P. Salinas (2007), p. 865.

${ }^{11}$ Ovidio (2001), pp. 295-296.
} 
sombrilla corta. Los árboles que se entrevieron un instante, fuera y en último término, antes de que la puerta se cerrara, no eran ya, transmutados por la figura femenil a que servían de momentáneo fondo, humildes acacias municipales el jardinillo de la plaza de la Catedral, sino una espesa selva de Argólida, que recorría ardorosa y virgen, esta Diana cazadora, toda extrañada de haber dado en medio de ella con un edificio raro y de bárbaras proporciones, con una catedral gótica. ... Diana se quedó parada, sin paso, sin voz, sin alma, ante una edad nueva. Y entonces perversa y femenina con su poder divino, en una hábil metamorfosis no ovidiana, tomó la apariencia respetuosa y tímida de una señorita que llega tarde a la catedral, la figura misma, los rasgos exactos de Matilde ${ }^{12}$.

La asimilación en este caso tiene un carácter más decorativo: la muchacha es comparada con una diosa en el esplendor de su belleza; pero que sea Diana y no Venus, por ejemplo, parece tener que ver principalmente con su atuendo (esa sombrilla que se asemeja a un carcaj) y su carácter decidido. El umbral que cruza al entrar en la catedral es también el que divide la ficción y la realidad cotidiana que describe el relato, ya que la detención momentánea que sirve habitualmente para acostumbrar la mirada a la luz del interior se convierte en un vaciamiento («sin paso, sin voz, sin alma») que a su vez deja paso al personaje «real». El umbral, sin embargo, no acaba de perder su carácter mítico: «salieron juntos, perseguidos, echados, como de un frustrado paraíso, por las llaves y el paso del sacristán. Pero Ángel sentía un placer satánico y secreto, porque él se marchaba con Matilde, andando a su lado, de carne y hueso, por una tarde palpitante y verdadera» ${ }^{13}$. El diálogo entre ficción y realidad abarca también otros aspectos del relato (por ejemplo, el rival que forma el trío al que alude el título es la estatua de Alfonso de Padilla) y queda fuertemente subrayado en esta frase, con la que concluye.

Al reseñar Víspera del gozo, uno de los temas que debatieron los críticos fue su relación con la obra de Proust, que Salinas acababa de traducir. Azorín, al explicar cuál es la diferencia entre ambos autores, explica que «el novelista [Salinas] está viendo a su amada - y está esperando su visión-, no de un modo directo, franco, como Proust, sino indirectamente, como si se tratara no de las especies de las cosas, sino del reflejo de esas cosas en múltiples espejos» ${ }^{14}$. El subrayado es del propio Azorín, y marca precisamente el término clave en la definición moderna del mito según las teorías de Ortega. Aquí mirada indirecta, oblicua, sobre el mito, no tiene tanto una función subversiva como autorreferencial: crea la distancia que permite a Salinas dar el salto hacia lo metatextual. También Fernando Vela, en la Revista de Occidente, liga este texto de manera directa a La deshumanización del arte, y

\footnotetext{
12 P. Salinas (2007), pp. 867-868.

${ }^{13}$ P. Salinas (2007), p. 868.

${ }^{14}$ Azorín (1926), p. 4.
} 
afirma que en «los cuadros de Víspera del gozo, vemos que predomina el juego de los mecanismos puramente artísticos» ${ }^{15}$. Así pues, en este caso, Salinas apuesta decididamente por un arte artístico, en el que el proceso de construcción y el carácter objetual quedan puestos en evidencia. El aspecto cómico y satírico no tienen peso en «Cita de los tres», pero sí están presentes, como señas de identidad ineludibles de la narrativa española de vanguardia, el humor en el juego de imágenes y el tratamiento voluntariamente frívolo y galante de la mitología.

Otro ejemplo significativo del recurso al mito, con carácter muy diferente, es Los terribles amores de Agliberto y Celedonia (1929), de Mauricio Bacarisse. En la larga dedicatoria a Ramón Gómez de la Serna que abre su novela, explica este autor cuáles son «los tres o cuatro temas cardinales [de la obra]:

la supremacía de la sugestión verbal; la superioridad combatiente de los mitos de la realidad y de la acción sobre los mitos de la fantasía, como facultad mucho más económica y previsora de lo que se dice, y, por último, la afirmación de que el amor material estimado como instintivo en las civilizaciones más insensibles y bárbaras, es lo menos material que hay en el mundo ${ }^{16}$.

Para cumplir estos objetivos, la novela se sirve de la estructura del triángulo amoroso y presenta las dudas de Agliberto, que se debate entre casarse con Mab, la mujer perfecta para él, y Celedonia, una joven imprevisible que acaba imponiéndose en su decidida realidad. Aunque la novela es larga y prolija, Bacarisse afirma que en su construcción decidió que el peso de la psicología y la acción debía recaer en uno solo de sus personajes:

\begin{abstract}
Según la técnica también clásica del análisis psicológico en la novela, he procedido sobre un solo personaje, Agliberto en este caso, pues no se puede hacer patente un intento de descomposición en más de uno de los caracteres. Tanto Mab como Celedonia están tratadas de modo legendario o mítico. Su prestigio de irrealidad, de inverosimilitud, así como la intervención de la sirena, mero ardid novelesco, creo que simplifican y aclaran el desarrollo de los hechos y la repercusión de estos en la conducta del protagonista ${ }^{17}$.
\end{abstract}

Así pues, al hablar de los personajes en Los terribles amores de Agliberto y Celedonia es necesario distinguir entre el encarnado por Agliberto, definido por su psicología, y el que aquí representan las mujeres, construidas sobre un entramado que Bacarisse entiende como arquetípico y estereotipado. Celedonia representa los

\footnotetext{
${ }^{15}$ F. Vela (1926), p. 128.

${ }^{16}$ M. Bacarisse (2004), p. 121.

${ }^{17}$ M. Bacarisse (2004), p. 122.
} 
«mitos de la realidad y la acción» y ese amor material que «es lo menos material de este mundo» y Mab «los mitos de la fantasía» ${ }^{18}$, que resulta a fin de cuentas una facultad más conservadora de lo que podría sospecharse.

La novela comienza transcribiendo el pensamiento de Agliberto en el estado de duda que le es propio, pero tardaremos un tiempo en saber quién es la persona que así piensa y actúa. El tono intensamente metafórico del texto permite que puedan compartir el protagonismo con Agliberto dos mujeres que son otras tantas abstracciones: un constructo mental (Mab) y la realidad con todo lo que tiene de atractivo e impredecible (Celedonia). Para conformar estas mujeres Bacarisse utiliza un recurso que llama mitificación, pero que no es propiamente tal, sino una personificación que en todo momento se muestra como proceso, y no sólo como resultado final ${ }^{19}$. Mab es resultado de un sueño de Agliberto, la personificación de sus patrones de mujer ideal. Celedonia es una antigua conocida del protagonista, por la que no siente ninguna atracción y cuyo nombre le resulta tan repelente que supone una barrera infranqueable entre los dos. Mab, siendo "perfecta», no tiene vida propia, y no consigue seducir al protagonista. Sin embargo Celedonia, que acompaña a Agliberto en su viaje a Portugal, al compartir sus vivencias muestra una personalidad inesperada y desconcertante que acaba resultando, en su realidad, irresistible.

Junto a la pseudo mitificación que Bacarisse hace de las protagonistas también encontramos la utilización de mitos tradicionales para ilustrar determinadas reflexiones. Dos son especialmente llamativos: la sirena y don Juan. En un viaje a la playa, Celedonia quiere darse un baño en el mar y sale de la caseta «radiante, fresca, ágil, Astarté recién nacida de un mito de última moda» ${ }^{20}$. Cuando entra en el agua, desaparece de la vista de Agliberto y en su lugar surge una sirena. El protagonista no piensa en una metamorfosis, y sigue buscando a su compañera hasta que se deshace el hechizo. Este episodio sirve para que el narrador haga una serie de digresiones (académicas, humorísticas) sobre la sirena y, sobre todo, para que explique su carácter híbrido, de lugar intermedio entre las dos mujeres entre las que se debate el protagonista, la soñada y la real:

\footnotetext{
${ }^{18}$ El nombre probablemente esté inspirado en «Queen Mab», de Shelley, que simboliza que «soul is the only element».

${ }^{19}$ De hecho, para Bacarisse (licenciado en cultura clásica y traductor de Platón y Sófocles), el mito es un esquema vivo de construcción, tiene función estructural, más que etiológica o incluso temática. Así lo comenta en el prólogo de su poemario Mitos (en M. Bacarisse, 2004, p. 89). Aunque hay innumerables perspectivas sobre el mito, para contrastar la de Bacarisse con la que se ha manejado a lo largo de la historia de la literatura aconsejo acudir a la que ofrece Losada Goya en «Mito moderno y proceso de mitificación» (J.M. Losada Goya, 2010).

${ }^{20}$ M. Bacarisse (2004), p. 211.
} 
Pero una mitad de mi ser es femenina, aunque la otra sea mito, de mentira, de fantasía arrolladora, de instinto ciego y arcano azul. No me ofendas en lo que poseo de humano y semejante a ti, aunque no te dignes aceptar lo que tengo de bestia inferior peligrosa e imposible ${ }^{21}$.

Esta escena tiene un gran valor simbólico, ya que Bacarisse da el nombre de «Sirena» a toda la primera parte del libro, en la que las dudas de Agliberto se mantienen equilibradas. En la segunda parte, titulada «Mab», la balanza va a ir cayendo poco a poco del lado de la realidad. Precisamente, la función de Don Juan (protagonista de uno de los capítulos finales) es «ratificar a Agliberto en la vía de la experiencia antes que del prejuicio o la teoría asépticamente programada» ${ }^{22}$. El protagonista se va convenciendo de que la imaginación es mucho más reducida que la rica realidad, que es preciso dejar que las previsiones mentales sean sobrepasadas por las sorpresas de la vida, más pródigas que los sueños. «La novela invita a proteger el vitalismo, el amor imprevisto y la libertad de la experiencia reflexiva frente a toda cortapisa, la peor de todas la sumisión del deseo y la voluntad al cálculo mezquino de conveniencias materiales» ${ }^{23}$.

El epílogo de la novela, en continuidad con la distancia con la que a lo largo de la obra el narrador trata a sus protagonistas, y en sumisión a la moda pirandelliana y unamuniana, da un paso metatextual. Agliberto va a hablar con el Novelista para presentarle su caso y pedirle un diagnóstico. Ródenas de Moya, en su detenido análisis de los segmentos autorreferenciales de la obra ${ }^{24}$, explica que no se trata propiamente de una intervención del autor en el mundo de los personajes sino de la creación un personaje más (que provoca una ruptura en la lógica narrativa que define como «metalepsis representada»). Si Celedonia y Mab son constructos que sirven al protagonista para reflexionar sobre la realidad y la imaginación, el Novelista es el personaje que permite al autor reflexionar sobre la función específica del escritor.

En suma, aunque sigue al pie de la letra el consejo de Ortega de hacer del protagonista y su desarrollo psicológico el centro del relato, también Bacarisse apuesta por una novela intelectual, con alusiones míticas, dirigida a un público culto capaz de disfrutar con las convenciones culturales y los juegos retóricos.

${ }^{21}$ M. Bacarisse (2004), p. 248.

22 J. Gracia (2004), p. L.

23 J. Gracia (2004), p. LV.

${ }^{24}$ D. Ródenas de Moya (2009). 
Entre otros muchos posibles ${ }^{25}$, quiero poner como último ejemplo Lo rojo y lo azul de Benjamín Jarnés (1932). Jarnés es también autor de «Nova novorum» (El profesor inútil y Paula y Paulita). Lo rojo y lo azul es posterior al cierre de la colección y fue publicado en Espasa-Calpe.

El libro, cuyo título evoca inmediatamente Le Rouge et le noir, se subtitula «Homenaje a Stendhal». Este autor, al que también Ortega admiraba ${ }^{26}$, atrae a Jarnés por sus personajes ricos, redondos, completos y de carácter moderno. En concreto, en Sorel ve ««un joven insolente, vivaz, desdeñoso...», siempre un individuo único, complejo y completo, nunca esa abstracción que es el «tipo», trazado en un estilo «nervioso, impertinente, desnudo»» ${ }^{27}$. El escritor aragonés, sin embargo, no es especialmente prolijo a la hora de describir al protagonista de su versión. La presentación es breve: «tenía veintiún años y un programa vital completamente en blanco. ... Era recluta del último remplazo y tránsfuga de un taller sacerdotal. Huérfano y sin fortuna. Solo frente al mundo» ${ }^{28}$. El somero retrato físico no llega hasta el comienzo de la segunda parte: «aquel recluta flacucho, de ojos infantiles, de manos finas, delgadas, que recorrían nerviosamente el menudo Olimpo encarcelado sobre el mostrador, produjo desde el primer día una extraña impresión en ambas Cecilias» ${ }^{29}$. Con estos pocos rasgos se señala la relación de Julio con el personaje de Stendhal, aunque esta va mucho más alláa ${ }^{30}$.

El escritor parece seguir a Ortega en Ideas sobre la novela cuando hace de Julio el núcleo del relato: la trama está trazada como un contexto que nos guía a través de la evolución de sus ideas. Sin embargo, no crea en ningún momento un ambiente totalmente realista y cerrado sobre sí mismo: precisamente uno de los elementos que aportan apertura y fuerza de modernidad al relato es la manera particular que tiene Jarnés de tratar el mito.

${ }^{25}$ Otros relatos vanguardistas con temática mítica son Medusa artificial, de Francisco Ayala (1928), La Venus mecánica, de José Díaz Fernández (1929), La túnica de Neso de Juan José Domenchina (1929), Geografía (1929), de Max Aub; Luna de copas (1929), de Antonio Espina o Hermes en la vía pública (1934), de Antonio de Obregón.

${ }^{26}$ Especialmente porque no nos refiere quién es o qué hacen sus personajes, sino que los presenta con detalle delante de nuestros ojos para que los juzguemos por nosotros mismos (J. Ortega y Gasset, 1982, p. 50).

${ }^{27}$ D. Ródenas de Moya (1999), p.35.

${ }^{28}$ B. Jarnés (2010), p. 20.

${ }^{29}$ B. Jarnés (2010), p. 71.

${ }^{30}$ De hecho, trasciende desde los escritos hasta la realidad: Jarnés se sentía especialmente identificado con Sorel por ciertos rasgos de su carácter y determinados episodios de su propia trayectoria vital. Julio Aznar, personaje que recorre varias de sus novelas, revela rasgos de carácter autobiográfico que hacen de él un alter ego del propio Jarnés (véase A. Pego, 1999, p. 159). 
En el breve relato «Discurso a Herminia» (1933), que publicó en Revista de Occidente y que más adelante sería el prólogo a la segunda edición de El profesor inútil, Jarnés defiende que el mito forma parte del ser humano y su historia, y que por tanto su reaparición en cualquier contexto resulta inexorable:

Si un dios o un subdios quieren volver a saltar a la tierra, desde el fondo de incógnitas mansiones, ¿quién puede impedirlo? Saltarán por encima o por debajo de toda cautela civil y de toda censura eclesiástica. Los dioses están siempre aquí a unos kilómetros o a unos pasos, y, de vez en cuando, graciosamente, nos tocan en el hombro, nos hacen volver la cabeza, se nos muestran bajo un disfraz de chófer, de gañán o de mecanógrafa. ... Estamos rodeados de Antígonas y de Edipos, de Narcisos y Junos ${ }^{31}$.

Así pues, no es extraño que en la vida de Julio (y Cecilia) se puedan descubrir también rasgos que actualizan relatos míticos. A través de ellos, «Jarnés logra dar consistencia psicológica a sus personajes, que emulan al personaje consagrado por la tradición, y puede llegar en otras a determinar la trama que se convierte en una paráfrasis más o menos libre de la vida del personaje evocado» ${ }^{32}$. En el caso que nos ocupa, el tratamiento mítico se aplica de manera directa a la protagonista femenina, y a través de ella al resto de los personajes.

En uno de sus paseos por el Paralelo barcelonés, Julio Aznar se enamora de Cecilia, una joven que trabaja en un quiosco vendiendo libros, periódicos y postales eróticas. Al hacer un segundo viaje a la tienda, Julio «vio sorprendido que un grupo de camaradas de pelotón prorrumpía en gruñidos de voluptuosidad ante el mitológico escaparate» ${ }^{33}$. Este espectáculo le hace reaccionar pensando que «son unos cerdos», y la lógica le lleva a ver en la bella quiosquera una revitalización de Circe. Esta imagen define la mirada de Julio sobre Cecilia: para cortejarla, entra en su establecimiento y le pide reproducciones de cuadros hasta que encuentra y le compra el de la diosa hechicera. Una vez que ella entiende el juego, a su vez lo llama Ulises ${ }^{34}$.

No se trata de una comparación aislada: las historias míticas se van entretejiendo a lo largo de la narración haciendo de los personajes seres que combinan la singularidad con cierto carácter arquetípico: sus acciones y los efectos de estas están marcadas por los esquemas propios de las narraciones clásicas. Así, la hermosura de Cecilia tiene efectos perversos:

\footnotetext{
${ }^{31}$ B. Jarnés (1999), p. 97.

${ }^{32}$ M.P. Martínez Latre (1989), p. 135.

${ }^{33}$ B. Jarnés (2010), p. 55

${ }^{34}$ B. Jarnés (2010), p. 69.
} 
En el pan de su belleza, cuyas migajas ideales llegaban hasta los compañeros de Julio, aquellos malignos dedos habían ya deslizado el veneno homérico, y los infelices reclutas, en triste reata, corrían a precipitarse en las abigarradas pocilgas del Paralelo y sus contornos ${ }^{35}$.

Sin embargo, la Circe de Jarnés ha perdido todo su aspecto trágico. Si en «la epopeya homérica, [estaba] dotada de una belleza seductora y hechicera, será ahora una bella burguesita del Paralelo» ${ }^{36}$. Colaboran a su degradación las constantes alusiones eróticas, rasgo identificador de Jarnés, que quiere con ellas plantear una postura vital, «un ideal absoluto y totalizador» ${ }^{37}$ con el que hace frente a las posturas morales y sociales que defendían las instituciones que en aquel momento ostentaban el poder.

Podemos ver, por tanto, que Jarnés no toma el mito en su vertiente trágica, sino que, como anunciaba Ortega en Meditaciones del Quijote, lo subvierte de modo que no solo veamos en él la llamada a lo esencial que le es inherente, sino principalmente su vigencia en la vida contemporánea. Para ello, además, se sirve de juegos de palabras e imágenes llenas de humor y de ingenio. De este modo, apelando a la imaginación, utilizando la agudeza verbal y adoptando una actitud lúdica, el texto se llena de recursos que acompañan las reflexiones intelectuales para hacer la novela más asequible y burlesca.

Tras una serie de peripecias, en la tercera parte, la novela toma un derrotero social y será la propia ciudad de Barcelona la que aparezca como una «gran Circe [que] le ha hecho arder, consumirse, como una pobre bujía que sueña ser astro» ${ }^{38}$. Estas inquietudes del final de la novela parecen demandar las tradicionales formas realistas. De hecho, encontramos entremezclados con la ficción hechos históricos tan concretos como la rebelión anarquista de Ángel Chueca en el Cuartel del Carmen de Zaragoza en enero de 1920. Este interés social, «la postura antibelicista, la crítica del progreso y la moral utilitaria, la reflexión sobre el papel del escritor en la modernidad» muestra que las narraciones inmediatamente anteriores a la guerra están ya «"contaminadas» por lo humano»" ${ }^{39}$. También puede observarse esta deriva en la descripción del personaje: abundan hacia el final los elementos de descripción psicológica como los relatos de recuerdos y los sueños ${ }^{40}$ o los razonamientos

\footnotetext{
${ }^{35}$ B. Jarnés (2010), p. 56

${ }^{36}$ M.P. Martínez Latre (1989), p. 137.

${ }^{37}$ V. Fuentes (1989), p. 74.

${ }^{38}$ B. Jarnés (2010), p. 115.

${ }^{39}$ E. Díaz (1994), p. 102, y J.J. Lanz (2003), p. 179.

${ }^{40}$ B. Jarnés (2010), pp. 170-173.
} 
interiores $^{41}$. Incluso en el tono general del relato: en su cierre, sin llegar a ser trágico adquiere tintes mucho más serios y comprometidos.

Sin embargo, las imágenes tomadas del arte o la mitología siguen presentes en esta última parte aportando una cierta dimensión supratemporal a los anhelos que representan los sublevados. De ahí que se puedan aplicar a Jarnés los criterios del «narrador joven» vanguardista al que se refiere Domingo Ródenas: un autor que «no elabora sus criaturas con acomodo imperfecto a un patrón realista sino de acuerdo con una técnica, digamos, de agregación de rasgos en torno a un núcleo caracterizador, sin que importe el grado de verosimilitud que obtenga en el resultado» ${ }^{42}$.

En efecto, Julio y Cecilia son reflejo de una apuesta decidida por lo intelectual: Julio está inspirado en Julián Sorel, Cecilia en Circe. No son recreaciones de sus referentes, sino que buscan demostrar que tras la realidad ordinaria están los grandes personajes de la novela y la mitología. En este proceso Jarnés no pone tanto el acento en el engrandecimiento de lo cotidiano como en la necesidad de mirar el mito y las grandes obras de arte de manera oblicua, subversiva, de modo que podamos verlas encarnadas en la dimensión material de la vida plebeya. De este modo, sin renunciar al arte que reflexiona sobre sí mismo, busca crear novelas cercanas y atractivas para la mentalidad contemporánea.

El estudio de los protagonistas de estas tres obras permite establecer algunas conclusiones sobre la influencia de las tesis Ortega y Gasset en la construcción de los personajes de la novela vanguardista.

En líneas generales, se puede decir que los narradores de los años 20 tomaron de Ideas sobre la novela el consejo de hacer del proceso psicológico del protagonista el centro del relato. Este personaje es habitualmente un hombre corriente, «plebeyo», y el narrador nos muestra sus peripecias desde una perspectiva cómica; aunque es preciso matizar que con la llegada de los años 30 la novela va adquiriendo una postura más grave y comprometida. También tuvieron presente los autores la idea del hermetismo, ya que estas novelas son mundos con leyes propias. La diferencia estriba en que Ortega proponía en Ideas sobre la novela que el microcosmos creado no tuviera rasgos fabulosos, sino que se circunscribiera a la realidad cotidiana. En los relatos que hemos visto, sin embargo, encontramos que a la hora de crear los personajes aparecen una y otra vez elementos «trascendentales ... que solo funcionan referidos al horizonte de cada individuo» ${ }^{43}$, como las alusiones intertextuales a la propia escritura o al mito. Es decir, son los elementos

${ }^{41}$ B. Jarnés (2010), pp. 175-178.

${ }^{42}$ D. Ródenas, p. 51. Ver también G. Pérez Firmat (1993), pp. 43-44 y p. 170.

${ }^{43}$ J. Ortega y Gasset (1982), p. 46. 
de ficción los que conforman la realidad autónoma de la novela como un mundo singular de carácter autorreferencial. De ahí que, a fin de cuentas, la novelas de los años veinte acabaran inclinándose hacia el modelo de arte moderno que Ortega describía en La deshumanización del arte: un arte convencional que no tiene una referencialidad natural, sino que focaliza principalmente su propio proceso de construcción. Así, los personajes no llegan a conformar una figura material plena, sino que conservan cierto carácter de esquema, acentuado por el carácter fragmentario de la estructura novelesca. Ya no vamos a encontrar una representación mimética de las personas, con su biografía y sus pasiones, sino sujetos sobre los que se nos ofrecen datos que no llegan a ser suficientes para crear un personaje redondo.

Quizá por eso, el mito juega en estas obras un papel principal. Desde las Meditaciones del Quijote hasta su obra póstuma, La idea de principio en Leibniz, Ortega se pregunta «si hay, si puede haber otras 'cosas poéticas en sí' aparte de las mitologías» ${ }^{44}$. Los narradores vanguardistas no se plantean esta cuestión en toda su radicalidad: el sustrato de sus protagonistas radica en ser sujetos de pensamiento. Sin embargo, se sirven del mito para dar consistencia y personalidad a estos seres que corrían el peligro de quedar reducidos a una mera abstracción. Las peripecias que la tradición asocia a los dioses del Olimpo sirven también para hacer avanzar la acción. Por último, su presencia en el relato permite vincular estas narraciones modernas con la tradición, mientras que la mirada oblicua con la que se abordan muestra el trayecto recorrido desde la antigüedad grecolatina hasta la España de los años 20.

\section{Obras citadas}

AZORÍN: «El arte de Pedro Salinas», ABC 9 Jul. 1926, pp. 3-4.

(http://hemeroteca.abc.es/nav/Navigate.exe/hemeroteca/madrid/abc/1926/07/ 09/003.html)

BACARISSE, Mauricio: Los terribles amores de Agliberto y Celedonia, en Obras, Madrid, Fundación Santander Central Hispano, 2004, pp. 121-417.

BELTRÁN ALMERÍA, Luis: «Estética de la novela en España. Tres momentos:

Ortega, Bergamín y Mariano Baquero Goyanes», Revista de Literatura LXXI, 141 (2009), pp. 157-170.

${ }^{44}$ Véase Pino Campos (2006), p. 771. 
(http://revistadeliteratura.revistas.csic.es/index.php/revistadeliteratura/article/ view/81/87)

DÍAZ, Epicteto: «Tres narradores de vanguardia: Antonio Espina, Benjamín Jarnés y Mario Verdaguer», Dicenda. Cuadernos de Filología Hispánica, 12 (1994), pp. 87-102.

(http://dialnet.unirioja.es/servlet/listaarticulos?tipo_busqueda=EJEMPLAR\& revista_busqueda $=417 \&$ clave_busqueda $=9152$ )

FERNÁNDEZ URTASUN, Rosa: «El mito en la novela vanguardista española: una mirada oblicua sobre la realidad», en José Manuel Losada y Marta Guirao (eds.), Myth and Subversion in the Contemporary Novel, Cambridge, Cambridge U P, 2012, pp: 67-80.

FUENTES, Víctor: «Jarnés: metaficción y discurso estético-erótico», en Jornadas jarnesianas, Zaragoza, Institución Fernando el Católico, 1989, pp. 65-76.

GRACIA, Jordi: «Mauricio Bacarisse o el arte de la reticencia», en Mauricio Bacarisse, Obras, Madrid, Fundación Santander Central Hispano, 2004, pp. XI-LV.

JARNÉS, Benjamín: Lo rojo y lo azul, Madrid, Salto de Página, 2010.

- El profesor inútil, Madrid, Espasa-Calpe, 1999.

LANZ, Juan José: «Entre deshumanización y rehumanización: Perspectivas orteguianas en Locura y muerte de Nadie, de Benjamín Jarnés», en Bulletin Hispanique 105, 1 (2003), pp. 175-213.

LOSADA GOYA José Manuel: «Mito moderno y proceso de mitificación», en Mito y mundo contemporáneo, Bari (Italia), Levante Editori, 2010, pp. 559-578.

MARÍAS, Julián: «Introducción», en José Ortega y Gasset, Meditaciones del Quijote, Madrid, Cátedra, 2005, pp. 15-32.

MAGNIEN, Brigitte: «Crisis de la novela», en Carlos Serrano y Serge Salaün (eds.), Los felices años veinte: España, crisis y modernidad, Madrid, Marcial Pons, 2006, pp. 233-301.

MAINER, José-Carlos: Historia de la literatura española. 6, Modernidad y nacionalismo 1900-1939, Barcelona, Crítica, 2010.

MARTÍNEZ LATRE, María Pilar: «La Mitología en las novelas jarnesianas», en Jornadas jarnesianas, Zaragoza, Institución Fernando el Católico, 1989, pp. 127-148.

MORÓN ARROYO, Ciriaco: «Estética», en El sistema de Ortega y Gasset, A Coruña: Mendaur, 2011, pp. 405-436.

ORTEGA Y GASSET, José: La deshumanización del arte, Madrid, Austral, 2008.

- Meditaciones del Quijote, Madrid, Cátedra, 2005.

- Ideas sobre el teatro y la novela, Madrid, Alianza, 1982.

OVIDIO: «Eco y Narciso», en Metamorfosis, Madrid, Cátedra, 2001, pp. 293-300.

PEGO PUIGBÓ, Armando: «Las novelas de un biógrafo (Benjamín Jarnés)»,

Dicenda. Cuadernos de Filología Hispánica 17 (1999), pp. 157-176. 
(http://dialnet.unirioja.es/servlet/listaarticulos?tipo_busqueda=EJEMPLAR\& revista_busqueda $=417$ \&clave_busqueda $=9157$ )

PÉREZ FIRMAT, Gustavo: Idle fictions: the Hispanic vanguard novel, 1926-1934, Durham, Duke U P, 1993.

PINO CAMPOS, Luis Miguel: "El concepto de mito en la obra de Ortega y Gasset", en Juan Antonio López Férez (ed.), La mitología clásica en la literatura española. Panorama diacrónico, Madrid, Ediciones clásicas, 2006, pp: 757777.

RÓDENAS DE MOYA, Domingo: «Mauricio Bacarisse: la sedición mansa», en Travesías vanguardistas: ensayos sobre la prosa del Arte Nuevo, Madrid, Devenir/Juan Pastor, 2009, pp. 381-428.

— «Introducción», en El profesor inútil, Barcelona, Seix Barral, 1999, pp. 9-68.

- Proceder a sabiendas: antología de la narrativa de vanguardia española, 19231936, Barcelona, Alba, 1997.

SALINAS, Pedro: «Víspera del gozo», en Obras completas. I, Poesía, narrativa, teatro, Madrid, Cátedra, 2007, pp. 851-888.

VELA, Francisco: «Pedro Salinas: Víspera del gozo», Revista de Occidente, 13 (1926), pp. 124-129. 